\title{
A ESCOLA NA PERSPECTIVA DA EDUCAÇÃO INTEGRAL
}

http://dx.doi.org/10.5902/2318133829225

\author{
Fabricia Sônego \\ Escola Municipal de Ensino Fundamental Leonor Pires de Macedo, Brasil. \\ Maria Eliza Rosa Gama \\ Universidade Federal de Santa Maria, Brasil.
}

\begin{abstract}
Resumo
Neste artigo apresenta-se uma reflexão sobre a educação integral e a organização do trabalho escolar. Objetiva-se compreender a constituição da escola como instituição de ensino, relacionando-a à educação integral. A partir da abordagem qualitativa constatou-se que a escola que se apresenta na atualidade preserva muitas características trazidas ao longo de sua constituição, porém essas características não impedem a organização da escola de educação integral. Uma vez que essa se constitui pelas pessoas que fazem parte de sua dinâmica, a escola de educação integral se concretiza pelo trabalho coletivo da equipe diretiva, dos professores, dos funcionários, dos alunos, dos pais e da comunidade.

Palavras-chave: escola; forma escolar; educação integral.
\end{abstract}

\section{THE SCHOOL IN THE PERSPECTIVE OF INTEGRAL EDUCATION}

\begin{abstract}
This article presents a reflection on integral education and the organization of school work. It aims to understand the constitution of the school as an educational institution, relating it to integral education. From the qualitative approach it was verified that the school that presents itself today preserves many characteristics brought throughout its constitution, however these characteristics do not impede the organization of the school of integral education. Once this is constituted by the people who are part of its dynamics, the school of integral education is concretized by the collective work of the directive team, the teachers, the employees, the students, the parents and the community.

Key-words: school; school form; comprehensive education.
\end{abstract}


- ste artigo integra a pesquisa intitulada Possibilidades para a organização do trabalho escolar na perspectiva de uma proposta de educação integral, desenvolvida na Universidade Federal de Santa Maria e em uma escola pública de ensino fundamental.

A pesquisa partiu do estudo teórico sobre o tema e de dados coletados no contexto vivido em uma escola pública municipal. Assim, buscou-se verificar o que ocorre na escola, de forma geral, e de que maneira acontece a implantação da proposta de educação integral.

A escola é uma instituição onde todos nós passamos vários anos de nossa vida - é onde nos constituímos estudantes. A palavra escola tem sua origem na forma grega Skhole, e na forma latina Schola, significa um momento de lazer, um momento de descanso, estudo prazeroso ${ }^{1}$, lugar do ócio, tempo livre. Logo, a escola tem sua origem como um lugar frequentado por quem tivesse tempo livre.

A origem da escola está intrinsecamente ligada às relações de trabalho. Nas comunidades primitivas, os homens trabalhavam coletivamente para sua existência e, ao mesmo tempo em que se educavam, educavam as novas gerações. No Antigo Egito, a educação se dava a partir de preceitos morais e comportamentais. Na Grécia a educação iniciava na família e baseava-se em assistir e observar antes de começar. Em Roma, o primeiro educador era o pai. Mantinham, assim, o modo de produção comunal, em que tudo era feito em comum, não havendo divisão de classes. Trabalho e educação desenvolviam-se conjuntamente.

Segundo Saviani (2007), "o desenvolvimento da produção conduziu a divisão do trabalho e, daí, a apropriação privada da terra, provocando a ruptura da unidade vigente nas comunidades primitivas" (p. 155). Assim, teve início a divisão de classes entre os proprietários e os que não são proprietários de terra. Basicamente, os primeiros eram os detentores das terras enquanto os segundos eram os escravos, o que configurou o modo de produção escravista. Com a divisão de classes, passou-se a ter uma separação entre a educação dos homens livres - classe proprietária -, centrada em atividades intelectuais, e educação dos escravos - classe não proprietária -, centrada no trabalho. Da educação dos homens livres originou-se a escola. Saviani (2007) destaca que,

desenvolveu-se, a partir daí, uma forma específica de educação, em contraposição àquela inerente ao processo produtivo. Pela sua especificidade, essa nova forma de educação passou a ser identificada com a educação propriamente dita, perpetrando-se a separação entre educação e trabalho. (p. 155)

A partir desse momento, a escola se institucionaliza, junto com a evidência da divisão da sociedade em classes. A classe dominante, proprietária de terras, dispõe de tempo livre para organizar-se para a escola, enquanto a classe dominada, os não proprietários de terras, continua com a educação atrelada ao processo do trabalho. $\mathrm{A}$

${ }^{1}$ Conforme http://www.dicionarioetimologico.com.br/escola-liceu/, acesso em 09/07/16.

\begin{tabular}{|l|l|l|l|l|}
\hline Regae: Rev. Gest. Aval. Educ. & Santa Maria & v. 7 & n. 14 & Jan./abr. 2018
\end{tabular} p. $135-145$ 
escola segue relacionada aos modos de produção, sendo "o modo como se organiza o processo de produção - portanto, a maneira como os homens produzem os seus meios de vida - que permitiu a organização da escola como um espaço separado da produção" (Saviani, 2007, p. 157).

Na Idade Média a escola foi marcada pela influência da igreja e a educação cristã permanece por muitos anos como orientação nas escolas. Ainda com o modo de produção escravista, a sociedade feudal, que produzia para as necessidades de consumo, intensificou a produção gerando excedentes que ativaram o comércio, surgindo a sociedade capitalista e por sua vez o modo de produção capitalista. Nesse contexto, a escola tornou-se a viabilizadora do acesso a uma nova sociedade produzida pelos homens, por meio de uma cultura intelectual, em que a produção para subsistência deu lugar às trocas por meio de processos contratuais, que podiam ser aprendidos na escola pela leitura e escrita.

Após a Revolução Industrial, a escola novamente apresentou-se como a promotora do acesso a mais uma nova sociedade. Uma sociedade em que a operacionalização das máquinas trazidas pela revolução, podia ser aprendida na escola. A "fé foi substituída pela razão" e a educação cristã passou a dar espaço para uma escola baseada na educação científica, em que a universalidade, a gratuidade, a estatalidade e a laicidade emergiram como características da nova escola que se estabeleceu, nesse momento da história. A educação, como reflexo da sociedade, desencadeou a democratização do ensino e uma nova maneira de ver a escola. Para Teixeira (1996),

a forma democrática de vida funda-se no pressuposto de que ninguém é tão desprovido de inteligência que não tenha contribuição a fazer às instituições e à sociedade a que pertence; e a forma aristocrática, no pressuposto inverso de que a inteligência está limitada a alguns que, devidamente cultivados, poderão suportar o ônus e o privilégio da responsabilidade social subordinada os demais aos seus propósitos e aos seus interesses. (p. 23)

A partir disso, na sociedade democrática, ao contrário das sociedades aristocráticas, em que o nascimento em uma família proprietária de terras asseguraria o acesso escolar, o direito e o dever de estar na escola asseguram o acesso de todos à escola. A escola se apresenta de maneira igual para todos pela primeira vez em toda sua trajetória. Porém, conforme Teixeira (1996),

é verdade que a democracia, em seus documentos legais, sublinhava a liberdade de expressão, de reunião e de organização. Ao lado da liberdade de ir e vir, estas novas liberdades sempre se ergueram como as grandes liberdades da época. Mas não se estendiam elas senão àqueles poucos que formavam a classe ascendente. Todas essas liberdades estavam, com efeito, subordinadas a uma condição fundamental: a de educação. $O$ homem precisa educar-se, formar a inteligência, para poder usar eficazmente as novas liberdades. (p. 27)

A educação seguia com acesso restrito a poucos, na maioria das vezes privada, configurando-se como um direito fora do alcance do povo. Ainda segundo Teixeira (1996), "a caracterização da educação como direito individual, assegurado pelo Estado, isto é, 
como interesse público, é coisa relativamente recente e apenas nesse século devidamente generalizada" (p. 38). Nesse sentido, a escola democrática que emerge no contexto da sociedade democrática parece ser justa. Mas, essa idéia de escola justa surge em um contexto em que "as sociedades democráticas escolheram convictamente o mérito como um princípio essencial de justiça: a escola é justa porque cada um pode obter sucesso nela em função de seu trabalho e de suas qualidades" (Dubet, 2004, p. 541).

Porém, a partir dessa concepção a escola ignorou as diferenças individuais presentes no contexto escolar decorrentes das desigualdades sociais. A sociedade democrática, que postula a igualdade entre todos, não pode fechar os olhos para a história da escola, para a história da educação fortemente marcada pela divisão de classes e acreditar que somente o fato de dar as mesmas possibilidades a todos, promoveria a meritocracia de forma justa. Conforme Dubet (2004),

é preciso aprender a defender outros princípios de justiça e a combiná-los com um modelo meritocrático. É necessário introduzir uma dose de discriminação positiva a fim de assegurar maior igualdade de oportunidades. É preciso também garantir o acesso a bens escolares fundamentais, ou, para afirmar de modo mais incisivo, a um mínimo escolar. (p. 553)

A escola justa, numa sociedade democrática, se faz com ações que promovam a equidade de possibilidades. Como destaca o autor, promovendo a igualdade de condições independente das desigualdades sociais. Essas, fazendo parte da sociedade capitalista, tem a escola como promotora de ações que atenuem as desigualdades escolares, não produzindo, por sua vez, mais desigualdades sociais. Para Teixeira (1996),

a sociedade democrática só subsistirá se produzir um tipo especial de educação escolar, a educação escolar democrática, capaz de inculcar atitudes muito especiais e particularmente difíceis, por isto que contrárias a velhas atitudes milenárias do homem. Terá de inculcar o espírito de objetividade, o espírito de tolerância, o espírito de investigação, o espírito de ciência, o espírito de confiança e de amor ao homem e o da aceitação e utilização do novo - que a ciência a cada momento lhe traz - como um largo e generoso sentido humano. (p. 43)

Essa escola, baseada na abertura ao novo e que sabe conviver com o outro, será capaz de se fazer enquanto escola democrática que assume os princípios democráticos como alicerce de sua estrutura. A trajetória da escola deve culminar em uma instituição que precisa desempenhar verdadeiramente os preceitos democráticos da sociedade de que faz parte. Como pode ser visto nessa retrospectiva sobre a origem da escola, o contexto histórico e social sempre esteve atrelado à educação.

Segundo Canário (2006), "um balanço da educação no século XX é quase inevitavelmente um balanço da educação escolar, na medida em que a instituição escolar foi, progressivamente, tornando-se o único ponto de referência de toda ação educativa" (p. 13). Assim, o percurso da educação ao longo do tempo, é o percurso da escola, marcada pela hegemonia da forma escolar de ensinar que confere somente à escola o fazer da ação educativa, desvalorizando os saberes extraescolares, e tornando toda forma não escolar de aprendizagem, semelhante à escola. A invenção da forma escolar, 
segundo Vincent (2001), tem início entre os séculos 16 e 17, no período Medieval. Nesse contexto histórico aparece a relação social entre um mestre e um aluno. Essa relação precisa de um lugar diferente dos lugares onde se realizam as atividades sociais para se desenvolver: a escola.

Desse modo, estabeleceu-se um espaço fechado e um tempo previsto, compondo a forma escolar em seu aspecto organizacional. O aspecto pedagógico da forma escolar se realiza na produção das "disciplinas" escolares. Essas se dão nas relações de submissão aos princípios e regras que regem a escola. Para Vincent (2001), as características da forma escolar são "a constituição de um universo separado para a infância; a importância das regras na aprendizagem; a organização racional do tempo; a multiplicação e a repetição de exercícios" (p. 38). Dessa maneira, a função da escola é aprender a seguir regras, uma maneira de socializar-se, nas palavras do autor "o modo escolar de socialização" (Vincent, 2001, p. 38).

A forma escolar parte de uma concepção de que o que é ensinado vem de fora do contexto vivido, organizando os tempos em períodos de aula e os espaços em salas de aula. Esse modelo organizacional se naturalizou ao longo dos anos, sendo que a compartimentalização das disciplinas, dos horários e do currículo escolar como listas sequenciadas, permanece até hoje.

Conforme Arroyo (2012), o sistema escolar segue uma lógica temporal que o estrutura de forma sequenciada, e que, como citamos, foi instituída faz muitos anos. A escola organiza os tempos e os espaços do professor, do aluno e dos conteúdos. Segue uma lógica transmissiva em que os conteúdos a serem transmitidos são o eixo central das séries, disciplinas e cronogramas. Essa lógica apresenta um caráter que precede e acumula os conteúdos, em que um ano escolar precede o outro, um trimestre escolar precede o seguinte, onde a partir de um ritmo médio de aprendizagem, se organiza o currículo escolar.

Essa lógica temporal, rígida e duradoura, tem explicação, segundo o autor, na "relação entre o ordenamento do tempo escolar e a construção das idades e tempos de vida" (Arroyo, 2012, p. 200) em que foi sendo necessário "criar instituições e tempos específicos de socialização e formação de crianças, adolescentes e jovens" (p. 201) e com isso, a escola. E mesmo que hoje se discuta sobre a eficiência da forma escolar e até mesmo da escola, segundo Alarcão (2001), no momento em que vivemos,

mesmo que, por força das novas tecnologias, a aprendizagem desprendase da necessidade de espaços coletivos e tempos simultâneos, ela não deixará nunca de realizar-se em contexto, talvez em comunidades aprendentes interconectadas, às vezes globalmente interconectadas. Nem por isso se poderá deixar de pensar em escola. Com novas configurações; porém, na sua essência, escola. (p. 10)

Isso mostra que a escola segue como instituição educativa corresponsável, uma vez que não faz isso sozinha, pela formação dos seres humanos, em que, mesmo que a sociedade evolua, como evoluiu ao longo da trajetória da escola, essa se mantém a mesma. Conforme Gama e Terrazan (2015),

a escola é um exemplo de instituição tradicional que tem demonstrado uma imensa capacidade em sobreviver e a resistir às constantes transformações ocorridas na humanidade ao longo das últimas décadas. 
Assim como, também é um bom exemplo de instituições que mantém as características que possuíam no início de sua existência. Ficando a margem dessas discussões e renegando um papel social fundamental, de socialização dos indivíduos por meio dos conhecimentos que ensina. ( $p$. 17)

É a partir dessa desconexão com o mundo contemporâneo e da sua incapacidade de adequar-se às mudanças da humanidade de forma realmente coerente, que se constitui a escola atual, onde o sentido da instituição escolar encontra-se atrelado ao sentido de que educação se quer concretizar, mas que também se mantém enormemente distanciado do mundo atual. Esse descompasso da escola com a sociedade atual remete à questão: para que servem as escolas? Se essas não conseguem se manter atualizadas com o momento, mesmo depois de passar por diferentes contextos de existência, porque seguem existindo? E existem escolas em todo o mundo.

Segundo Young (2007), "para fins educacionais, alguns tipos de conhecimentos são mais valiosos que outros, e as diferenças formam a base para diferenciação entre conhecimento curricular ou escolar e conhecimento não escolar" (p. 1293). Esse conhecimento valioso, denominado pelo autor como conhecimento poderoso, é o que deve ser ensinado pela escola. Ensinar aos alunos um conhecimento que não é aprendido fora da escola: por esse motivo as escolas continuam a existir (Young, 2007). O conhecimento poderoso refere-se a fornecer explicações confiáveis ou novas formas de se pensar a respeito do mundo" (p. 1294). Esse é um conhecimento que independe do contexto em que se aprende e também é chamado de conhecimento teórico, é aprendido na escola. Diferentemente dos conhecimentos que dependem do contexto, que podem ser aprendidos nas atividades cotidianas.

A escola, ciente do conceito de diferenciação do conhecimento, serve para disponibilizar a todos que nela passam o conhecimento eficiente, a fim de "capacitar jovens a adquirir o conhecimento que, para a maioria deles, não pode ser adquirido em casa ou em sua comunidade, e para adultos, em seus locais de trabalho" (Young, 2007, p. 1294). Nesse sentido, a escola se torna um lugar de acesso ao conhecimento local e universal, decorrente de uma proposta curricular que diversifique as aprendizagens, aproxime-se do contexto social e evidencie o conhecimento poderoso. Para isso, é preciso uma nova racionalidade do que é a escola, do que queremos que seja a escola. Para Alarcão (2001),

essa nova maneira de pensar e de agir tem implicações ao nível da escola e reflete-se na maneira como se concebe a formação e o currículo, como os professores percebem e concretizam a sua prática pedagógica, como os alunos vivem o seu ofício de estudante. Além disso, repercute-se no papel que se atribui aos professores, aos alunos e aos funcionários e nas dinâmicas de desenvolvimento que as escolas introduzem. (p. 11)

Uma nova racionalidade de escola remete a um olhar criterioso para a escola, que perceba o que passa sem ser visto no cotidiano escolar, pois é o cotidiano da escola que a torna escola, nas ações pensadas ou não, dos professores, dos funcionários, da equipe diretiva, dos processos de gestão escolar. Ações permeadas pela concepção de cada um sobre o que é formação, o que é currículo, o que são as interações entre as pessoas que compõe a escola. $\mathrm{E}$ ainda, o que isso tem a ver com a escola enquanto instituição 
educativa. Diante disso, é necessário compreender como é a escola, como essa se organiza, como organiza suas atividades, seus valores, seu cotidiano, enfim, entender a cultura existente dentro da escola.

Para isso, partimos da idéia de Nóvoa (1992), de que a escola, como instituição educativa, organiza-se de acordo com três aspectos: estrutura física, a qual corresponde à dimensão da escola, a organização física dos espaços, dos recursos da escola, etc.; a estrutura administrativa, de que fazem parte a gestão, a direção, as decisões, os recursos humanos, etc.; e a estrutura social, em que está o relacionamento entre alunos, professores, funcionários, pais, enfim, a cultura organizacional da escola. Esses aspectos estão inter-relacionados dentro da escola, uma vez que não se apresentam separadamente no cotidiano escolar. Além desses aspectos, existem algumas características das instituições escolares que lhes conferem bom funcionamento, a saber: a autonomia e a liderança organizacional através do envolvimento da comunidade educativa na escola; a articulação curricular e a otimização do tempo.

Assim sendo, essas premissas determinam a melhor organização das aprendizagens; a estabilidade profissional e a formação de pessoal como aspectos de valorização e pertencimento dos professores à escola; a participação dos pais, o reconhecimento público e o apoio das autoridades, como forma de motivação aos envolvidos com a instituição escolar (Nóvoa, 1992). Essas características remetem à cultura organizacional da escola, que demonstram como é a escola a partir de valores, crenças, objetivos, currículo, linguagens, arquitetura, normas, procedimentos, etc., constituindo a cultura escolar presente nas escolas e que determina a concepção de escola e de educação presente em cada instituição.

A cultura escolar remete à formação e socialização do indivíduo, de forma que "toda educação é sempre educação de alguém por alguém” (Forquin, 1993, p. 10). Assim acaba por transmitir conhecimentos que já existem de forma que o que se ensina à alguém é um conteúdo que já foi aprendido por quem agora o ensina. Dessa forma, o conteúdo da educação, conforme Forquin (1993), é a cultura, mesmo sendo essa uma denominação muito ampla, visto que a cultura é "considerada como o conjunto dos traços característicos do modo de vida de uma sociedade, de uma comunidade ou de um grupo, aí compreendidos os aspectos que se podem considerar como os mais cotidianos, os mais triviais ou os mais inconfessáveis" (p. 11).

Por isso, o homem, como um ser de cultura, se relaciona por meio dessa, vive-a e transmite-a por meio das gerações. Segundo Forquin (1993, p. 13), a cultura "nos precede, nos ultrapassa e nos institui enquanto sujeitos humanos". Dessa forma, a educação e a cultura constroem e mantêm a experiência humana. Assim, a cultura se apresenta de forma coerente com cada contexto, visto que a cultura presente dentro da escola remete a um recorte de conteúdos pertinentes ao contexto escolar. A escola transmite apenas parte da cultura, pequenos recortes, idéias, formas de expressão, caracterizando a cultura escolar vivida no cotidiano da escola.

Mas e a escola de educação integral? Ou a escola de tempo integral? Escola integrada? Jornada ampliada? Que escola é essa? Pensar a escola na perspectiva da educação integral remete a perguntar-se que escola se almeja e o que se pretende com a educação integral. Olhar a escola na perspectiva da educação integral nos leva a observar atentamente a realidade escolar e o que se quer fazer a partir dela. No contexto 
em que vivemos, as legislações referem-se a uma escola de tempo integral, evidenciando a ampliação do tempo na escola. Porém, parece-nos evidente que ao promover-se uma escola de tempo integral, ampliando a jornada escolar, o que deverá ser desenvolvido nessa é a educação integral. Assim entendemos que a educação integral é o produto das escolas de tempo integral.

A educação integral engloba diferentes dimensões de formação do indivíduo, sendo essas cognitivas, afetivas, físicas, éticas, etc. Essas dimensões compõem a formação plena do ser humano e equiparam-se em grau de importância, visto que nenhuma é mais importante que a outra já que formam o todo: o ser humano. Nesse sentido, pensar a educação integral, é pensar na formação do ser humano completo, que se forma e se transforma a todo o momento e em todo lugar. A escola é, por sua vez, mais um lugar que proporciona momentos de formação do ser humano, como a família e os amigos. O tempo que cada pessoa fica na escola serve para oportunizar aprendizagens, logo, permanecer mais tempo na escola significa participar de mais momentos de aprendizagem e com isso ampliar o processo de construção do ser humano junto da escola. Entender a educação integral como uma rede de saberes que partem da escola e dos saberes escolares e ampliam-se aos saberes populares, é entende-la como um direito. Todos tem o direito de estar na escola e de aprender a partir dessa, seja no contexto escolar em si, ou no entorno da escola, aprendendo a partir do território que se abre para as vivências propiciadas pelas escolas de educação integral. Para Leite e Carvalho (2016),

assumimos aqui uma concepção de Educação Integral que vai além da expansão da jornada escolar, embora compreendendo que esta ampliação pode contribuir para o desenvolvimento da Educação Integral. Pressupõese que a questão do tempo estendido esteja aliada à ampliação das possibilidades formativas dos sujeitos. Aponta-se assim, para uma compreensão de educação Integral que seja capaz de desenvolver uma formação de crianças e jovens que tangencie os campos da cultura, da relação com a comunidade e com a família e do diálogo com o território. A ampliação do tempo dialoga, nessa perspectiva, com a vivência desse tempo estendido. (p. 1206)

Assim, a educação integral a que nós historicamente referimos, remete à formação do aluno a partir de saberes escolares - conteúdos científicos propriamente ditos - e saberes populares - do aluno, do professor, do cotidiano escolar, da rua, da comunidade e parte de uma premissa básica: da importância de ver a escola, ver o que se vive dentro da escola, dentro da vida escolar, como educação integral. A partir dessa visão, a educação integral se afirma como um direito de todo aluno e deixa de estar atrelada aos discursos de turnos e contra turnos, pois precisa ser entendida para além dessa discussão.

Nessa perspectiva, a educação integral parte de uma dinâmica curricular permeada por esse ver a escola. A proposta pedagógica da escola precisa formular-se a partir do cotidiano da escola de educação integral. Professores, alunos, funcionários, comunidade escolar precisam viver esse momento e juntos organizar ou re-organizar os documentos escolares, proposta político-pedagógica e regimento escolar, entendendo que esses documentos são o retrato da vida na escola e que precisam fazer parte do cotidiano de cada um. Esse movimento possibilita um processo de gestão que oportuniza a construção da proposta pedagógica da escola, a partir das práticas realizadas.

\begin{tabular}{|l|l|l|l|r|r} 
Regae: Rev. Gest. Aval. Educ. & Santa Maria & v. 7 & n. 14 & Jan./abr. 2018 & p. $135-145$
\end{tabular}


E, dessa forma, diminuir a distância entre os docentes e o currículo escolar, pois esse precisa ser entendido como os saberes escolares, necessários para a formação do aluno. O currículo visto dessa forma leva a entendê-lo como uma base de aprendizagens, flexível e aberto para agregar os demais saberes populares, saberes de vida e da comunidade e que dão significado e sentido à escola. $O$ trabalho de organizar essa dinâmica curricular permeada pela educação integral não é simples, requer reflexão coletiva do grupo envolvido. É isso, esse movimento coletivo, que possibilita a escola de educação integral. Um trabalho que é individual, mas, ao mesmo tempo e acima de tudo, é coletivo.

Construir junto com os alunos a idéia de trabalho coletivo, no qual professores e alunos aprendem juntos. Pensar nas atividades programadas, ver o que é feito em sala de aula e o porquê de ser feito. Estar ciente de nossas atividades enquanto docentes. Isso é fazer a escola de educação integral. Assim, não estaremos fazendo mais do mesmo, mas estaremos fazendo mais em conjunto e por isso tornando-o diferente. Esse mais é novo, é construído, é planejado pelo professor. O planejamento é próprio do processo de gestão da educação integral: a gestão docente, a gestão escolar e a gestão educacional. Cada processo de gestão faz sua parte para que a escola de tempo integral seja uma rede de saberes e oportunize as vivências esperadas e inesperadas.

Assim sendo, a escola de educação integral é uma proposta coletiva, planejada e sujeita à múltiplas aprendizagens. A escola de educação integral preconiza os conhecimentos universais, agrega os conhecimentos locais e entendidos como direito, apresenta-se como promotora de saberes e não como acolhedora social para classes populares. Conforme Coelho e Maurício (2016),

a tessitura das atividades diversificadas que a escola de tempo integral pode oferecer, reunindo os conhecimentos universais, historicamente construídos, e aqueles da cultura local, vai revelar os conhecimentos praticados por ela, na busca da inclusão das crianças no contexto da sociedade em que vivem, possibilitando-Ihes acessar e contribuir com toda a atividade humana que aquela cultura construiu. Para que tal compromisso possa acontecer - com qualidade - essa escola de tempo ampliado, precisa concentrar seus esforços nesse sentido. Quando, ao contrário, o compromisso primeiro evidencia a proteção integral da criança, outro projeto de sociedade está em curso. Não aquele que possibilita a emancipação, mas o que contém vários elementos que, ao incluírem, levam à exclusão. (p. 1109)

A escola que foi se delineando ao longo de sua trajetória e que resultou na forma escolar que conhecemos atualmente é a mesma que sediará as propostas de educação integral. Como vimos anteriormente, a estrutura organizacional da escola permanece a mesma desde sua institucionalização, o que nos leva a inferir que a consolidação da educação integral em nossas escolas está atrelada as ações e reflexões das pessoas que constituem a escola.

São os alunos, professores, funcionários, equipes diretivas, pais e comunidade que construirão as escolas de educação integral a partir de suas ações em busca da formação do ser humano. A escola de educação integral se faz pelos que nela acreditam e que 
ousam dar os primeiros passos a fim de construí-la. Diferente de todas as reformulações externas sofridas pela escola ao longo do tempo, a escola de educação integral precisa partir do interior da escola. Precisa ser construída pela comunidade escolar; precisa ter a identidade da escola.

\section{Referências}

ALARCÃO, Isabel (org.). Escola reflexiva e a nova racionalidade. Porto Alegre: Artmed, 2001.

ARROYO, Miguel G. Imagens quebradas: trajetórias e tempos de alunos e mestres. Petrópolis: Vozes, 2012.

ARROYO, Miguel G. Ofício de mestre: imagens e autoimagens. Petrópolis: Vozes, 2010.

CANÁRIO, Rui. A escola tem futuro? Das promessas às incertezas. Porto Alegre: Artmed, 2006.

COELHO, Lígia M. C. da. C. e MAURÍCIO, Lúcia V. Sobre tempo e conhecimentos praticados na escola de tempo integral. Educação \& Realidade, Porto Alegre, v. 41, n. 4, 2016, p. 1095-1112. Disponível em <http://dx.doi.org/10.1590/2175-623660598>. Acesso em 4 out. 2016.

DUBET, François. O que é uma escola justa? Cadernos de Pesquisa, v. 34, n. 123, 2004, p. 539-555. Disponível em <http://www.scielo.br/pdf/cp/v34n123/a02v34123.pdf>. Acesso em 20 set. 2016.

FORQUIN, Jean-Claude. Escola e cultura: as bases sociais e epistemológicas do conhecimento escolar. Porto Alegre: Artes Médicas, 1993.

GAMA, Maria Elisa R. e TERRAZAN, Eduardo A. O trabalho docente em uma escola pública de educação básica: entre a complexidade e a simplificação. Curitiba: CRV, 2015.

LEITE, Lúcia H. A. e CARVALHO, Paulo F. L. de. Educação de tempo integral e a constituição de territórios educativos. Educação \& Realidade, Porto Alegre, v. 41, n. 4, 2016, p. 1205-1226. Disponível em <http://dx.doi.org/10.1590/2175-623660598>. Acesso em 4 out. 2016.

NÓVOA, António (coord.). As organizações escolares em análise. Porto: Dom Quixote, 1992.

SAVIANI, Demerval. Trabalho e educação: fundamentos ontológicos e históricos. Revista Brasileira de Educação, v. 12, n. 34, 2007, p. 152-180. Disponível em <http://www.scielo.br/pdf/rbedu/v12n34/a12v1234.pdf>. Acesso em 20 set. 2016.

TEIXEIRA, Anísio. Educação é um direito. Rio de Janeiro: UFRJ, 1996.

VINCENT, Guy. LAHIRE, Bernard; THIN, Daniel. Sobre a história e a teoria da forma escolar. Educação em Revista, Belo Horizonte, n. 33, 2001, p. 7-47, 2001. Disponível em: <http://www.scielo.br/scielo.php?script=sci_nlinks\&ref=000228\&pid=S0102-

$4698201200010000300035 \&$ Ing=pt>. Acesso em 20 set. 2016.

YOUNG, Michael. Para que servem as escolas? Educ. Soc., Campinas, vol. 28, n. 101, 2007, p. 1287-1302. Disponível em <http://www.cedes.unicamp.br>. Acesso em 20 set. 2016. 
Fabricia Sônego tem mestrado em Políticas Públicas e Gestão Educacional pela UFSM e é supervisora pedagógica na Escola Municipal de Ensino Fundamental Leonor Pires de Macedo de Restinga Sêca/RS.

Endereço postal: Rua Isaltino de Oliveira, 823 - 97200-000 - Restinga Sêca - RS Brasil.

E-mail: fabriciasonego@gmail.com.

Maria Eliza Rosa Gama é professora na Universidade Federal de Santa Maria. Endereço postal: Av. Roraima, 1000 - 97105-900 - Santa Maria - RS - Brasil. E-mail: melizagama@yahoo.com.br.

Recebido em 25 de setembro de 2017. Aceito em 29 de novembro de 2017. 